\title{
Melanocytic nevi in sentinel lymph nodes: association with cutaneous nevi and clinical relevance in patients with cutaneous melanomas
}

\author{
Lutz Kretschmer ${ }^{1}$ (1) $\cdot$ Viktor Schnabel $^{1}$. Christian Kromer ${ }^{1} \cdot$ Christoph Bauer-Büntzel $^{2} \cdot$ Annika Richter $^{3}$. \\ Felix Bremmer ${ }^{3} \cdot$ Fabian Kück $^{4} \cdot$ Katharina Julius $^{1} \cdot$ Christina Mitteldorf $^{1} \cdot$ Michael P. Schön $^{1}$
}

Received: 6 December 2021 / Accepted: 19 December 2021 / Published online: 20 January 2022

(c) The Author(s) 2022

\begin{abstract}
Purpose Melanocytic nevi in lymph nodes (NNs) are an important histological differential diagnosis of initial sentinel lymph node (SN) metastasis in melanoma. Our aim was to associate NN in SNs with clinicopathologic features and survival rates in 1, 250 patients with SN biopsy for melanoma.

Methods To compare patients with present and absent NN, we used Fisher's exact test, Mann-Whitney $U$ test, and multivariate logistic regression models in this retrospective observational study based on a prospectively maintained institutional database.

Results NN prevalence in axillary, cervical, and groin SNs was $16.5 \%, 19.4 \%$, and 9.8\%, respectively. NN were observed in combination with all growth patterns of melanoma, but more frequently when the primary was histologically associated with a cutaneous nevus. We observed a decreasing NN prevalence with increasing SN metastasis diameter. Multiple logistic regression determined a significantly increased NN probability for SNs of the neck or axilla, for individuals with $\geq 50$ cutaneous nevi, midline primary melanomas, and for individuals who reported non-cutaneous malignancies in their parents. Cancer in parents was also significantly more frequently reported by melanoma patients who had more than 50 cutaneous nevi. In SN-negative patients, NN indicated a tendency for slightly lower melanoma-specific survival.

Conclusions We found a highly significant association between NN diagnosis and multiple cutaneous nevi and provided circumstantial evidence that cutaneous nevi in the drainage area of lymph nodes are particularly important. The trend toward lower melanoma-specific survival in SN-negative patients with NN suggests that careful differentiation of SN metastases is important.
\end{abstract}

Keywords Sentinel lymph node $\cdot$ Melanoma $\cdot$ Nodal nevus $\cdot$ Skin nevi

Abbreviations
MTD Maximum diameter of the largest intranodal
metastasis
NN Melanocytic nevi in (sentinel) lymph nodes

Lutz Kretschmer

lkre@med.uni-goettingen.de

1 Department of Dermatology, Venereology and Allergology, University Medical Center, Robert Koch Str. 40, 37075 Göttingen, Germany

2 Department of Nephrology and Hypertension, Center for Internal Medicine and Medical Clinic III, Klinikum Fulda, Fulda, Germany

3 Institute of Pathology, University Medical Center, Göttingen, Germany

4 Department of Medical Statistics, University Medical Center, Göttingen, Germany

$\begin{array}{ll}\text { SN } & \text { Sentinel lymph node } \\ \text { SNB } & \text { Sentinel lymph node biopsy } \\ \text { vs } & \text { Versus }\end{array}$

\section{Introduction}

Benign melanocytic nevus cell aggregates in lymph nodes, also called nodal nevi (NN), are typically located within the capsule or trabeculae of lymph nodes. NN were first depicted by Stewart and Copeland (1931). The described patient suffered from neurofibromatosis and a large bathing trunk nevus. Two different theories of $\mathrm{NN}$ histogenesis have been discussed, but none of them has gained general acceptance. Some authors consider NN to be remnants of embryonic migration of melanocyte precursors from the neural tube. The others favor a retrograde migration of 
nevus cells from the skin via afferent lymphatic vessels as causal.

Melanocytic nevi in sentinel lymph nodes (SNs) may cause diagnostic problems in patients with melanoma. An expert review of SN biopsy specimens found to be melanoma positive revealed that more than $10 \%$ were misclassified NN (El Sharouni et al. 2021). Misdiagnosis in the distinction between NN and SN metastases could result in over- or undertreatment. To date, the clinical significance of $\mathrm{NN}$ in $\mathrm{SNs}$ from patients with melanomas has rarely been investigated (Gambichler et al. 2013; de Beer et al. 2019; Yamashita et al. 2020). One objective of the present study was to correlate clinical and histological parameters with the presence of $\mathrm{NN}$ in SNs. In addition, our aim was to clarify the impact of the diagnosis of $\mathrm{NN}$ on the prognosis of sentinel-negative and sentinel-positive patients with melanomas.

\section{Methods}

Our local ethics committee approved this retrospective observational study (No. 4/5/15), based on a prospectively maintained database of the Göttingen University Medical Center. We identified 1250 patients with primary cutaneous melanoma who underwent sentinel node biopsy (SNB) between April 1998 and December 2017. Surgical and pathologic standards were ensured throughout the study period by staff consistency. Indications for SNB were a Breslow thickness of $\geq 1 \mathrm{~mm}$ or $<1 \mathrm{~mm}$ if the Clark level was $\geq I V$ or if regression, ulceration or nodal tumor growth were documented. We excluded 23 patients in whom a SN could not be detected during surgery. Of the 1227 patients with successful SNB, 1085 had a documented histologic examination regarding the presence or absence of $\mathrm{NN}$.

\section{Patient history and clinical examination}

We used an a priori designed patient questionnaire and a standardized protocol for the first clinical examination at the time of SNB.

\section{SN mapping technique}

Radioactive lymph nodes that appeared first during lymphoscintigraphy or displayed an afferent vessel were defined as SNs. During surgery, lymph nodes that stained blue or that emitted $\geq 10 \%$ of the radioactive signals of the most radioactive lymph node were defined as SNs (Kretschmer et al. 2015).

\section{Pathological SN assessment}

We processed SNs using an extensive multiple slice protocol as previously described (Kretschmer et al. 2021). The reporting required indication on the presence or absence of an NN in each individual SN. H\&E stains and the antibodies S100, Melan A, and HMB-45 were routinely employed. The immunohistochemical proliferation marker Ki-67 was used in difficult cases. NN were defined as monomorphous nests of melanocytes without cytological atypia, mitoses or prominent nucleoli, showing no or only weak HMB45 reactivity. Histologic diagnosis was also based on the localization of melanocytes within capsule or trabeculae of the lymph node. Melanoma cells, nevus cells and pigmented histiocytes were meticulously differentiated based on anatomic localization, cytological and immunohistochemical criteria (Scolyer et al. 2008).

\section{Statistical analyses}

The following medical history and clinical features were assessed for a relationship to NN prevalence: age, sex, history whether the melanoma arose from a pigmented mole, melanomas in parents or siblings, non-cutaneous malignancies in parents, Fitzpatrick skin phototype (I-IV in our sample), skin nevus count ( $<50$ vs. $\geq 50$ skin nevi), multiple lentigines solares, histological features of the primary melanoma (location histological association with skin nevus, growth pattern, Breslow thickness, ulceration), location of the leading lymph node basin, unidirectional vs. bi- or multidirectional lymphatic drainage, SN status, and maximal SN metastasis diameter (MTD).

For judging correlations, Pearson's correlation coefficient was used. To compare patients with NN present and $\mathrm{NN}$ absent, we used Fisher's exact test for nominal and the Mann-Whitney $U$ test for ordinal and metric variables. We further calculated odds ratios and their $95 \%$ confidence intervals $(95 \% \mathrm{CI})$. We took variables having a $\mathrm{p}$ value of less than 0.2 in the univariate analysis into consideration for multivariate logistic regression models. Of predictors that showed strong association with each other (e.g., midline location of the primary melanoma and bidirectional lymphatic drainage), only the most appropriate one was included in multivariate analyses. Kaplan-Meier analyses evaluated follow-up time and survival rates according to the presence or absence of $\mathrm{NN}$; the hazard ratio was calculated using Cox proportional hazards regression. Differences were compared with the log rank test. For statistical analyses, we used the statistical programming environment R (version 3.6.0; R Core Team 2018) and the statistical software package Statistica (Version 13.5 TIBCO 
Software). The significance level was set to $\alpha=5 \%$. Due to the exploratory nature of this study, no adjustment for multiple testing was applied.

\section{Follow-up}

The patients were monitored routinely at 3-month intervals for the first 5 years and every 6 months for the next 5 years, in accordance with valid guidelines in Germany (Pflugfelder et al. 2013).

\section{Results}

\section{Study population}

The median follow-up time was 85 months (range 3-249 months). Of the 1085 patients with a valid examination for NN, $530(48.8 \%)$ were female. The mean age was $58.5 \pm 16.8$ years, and the mean Breslow thickness was $2.4 \pm 2.3 \mathrm{~mm}$. Of the 1042 melanomas with an appropriate examination for ulceration, 291 (27.9\%) were ulcerated.

At least one NN was documented within one of the SNs in $170(15.7 \%)$ patients. The mean number of excised cervical, axillary and groin $\mathrm{SNs}$ was $2.9 \pm 2.0,2.0 \pm 1.3$, and $2.1 \pm 1.1$, respectively. The proportion of cases with bidirectional or multidirectional lymphatic drainage for neck, axilla, and groin was 35/135 (20.6\%), 139/454 (23.4\%), and $53 / 340(13.5 \%)$, respectively. Thus, the frequency of multidirectional lymphatic drainage in patients with lymphatic drainage in the groin was significantly lower than for the cervical or axillary location of the leading lymph node area combined $(P>0.001)$. NN prevalence in axillary, cervical, and groin SNs was $16.5 \%, 19.4 \%$, and $9.8 \%$, respectively.

\section{Clinicopathological characteristics according to the presence or absence of NN}

We observed $\mathrm{NN}$ in association with all histopathological growth patterns of primary melanoma. Specifically, NN prevalences according to growth pattern were: lentigo maligna melanoma $20 \%$ (9/45), superficial spreading melanoma $17.6 \%$ (73/415), nodular or superficial spreading melanoma with nodular component $14.2 \%$ (66/471), acral lentiginous melanoma 7\% (5/68), spitzoid melanoma $10 \%$ (3/30), desmoplastic melanoma $27.3 \%$ (3/8), nevoid melanoma $18.2 \%$ (2/13), malignant blue nevus $75 \%$ (3/4), and other rare growth patterns including melanoma of unclassifiable histogenetic type $30.8 \%$ (4/13). We compared other clinical and pathologic features according to the presence or absence of NN (Table 1). Regarding the leading nodal basin, NN prevalences in cervical and axillary SNs did not differ significantly $(P=0.40)$. SNs in the groin had a significantly lower prevalence. Accordingly, primary melanomas in the leg had a significantly lower NN probability than primary melanomas in the arm.

The NN rate was significantly higher in patients with multiple melanocytic nevi of the skin $(\geq 50)$. SNs were significantly more frequently positive for $\mathrm{NN}$, when they belonged to primary melanomas histologically associated with a melanocytic nevus.

We observed a significantly increased NN prevalence in patients who reported that one of their parents had a history of non-cutaneous malignancy.

Factors not significantly related to the presence of NN were, age, sex, the history of a mole preexisting the cutaneous melanoma, melanomas in relatives, Fitzpatrick skin phototype, the presence of multiple lentigines solares, Breslow thickness as a continuous variable, ulceration of the primary, and SN status.

In multiple logistic regression (Table 2), both the presence of more than 50 cutaneous nevi and nodal basins located in the upper half of the body were highly significant for increased NN probability. Midline-located primary tumors and history of non-cutaneous malignancies in parents also remained significant.

\section{Association of multiple cutaneous nevi with the history of non-cutaneous cancer in parents}

To further explain the surprising association between NN and family history of parental cancer, we also examined the association with multiple skin nevi. Patients with cutaneous high-risk melanomas who had multiple nevi of the skin reported significantly more often non-cutaneous cancer in parents $(20.9 \%$ vs. $14.0 \%, P<0.001)$.

\section{Peculiarities according to SN status}

\section{SN-negative subpopulation}

In the SN-negative subpopulation, the same factors were significant for $\mathrm{NN}$ that have already been described for the overall population prevalence (detailed results not shown). In contrast to the overall population, multiple solar lentigines also indicated a higher rate of NN (19.6\% vs. $13.7 \%$, $P=0.039$ ). The histologic association of a primary melanoma with a melanocytic nevus failed to reach significance to predict the NN rate $(20.1 \%$ vs. $14.6 \%, P=0.083)$.

In multivariate logistic regression (Table 3 ), the presence of more than 50 skin nevi and SNs draining the upper half of the body remained significant. 
Table 1 Univariate comparisons: sentinel node nevus according to clinical and pathological characteristics

\begin{tabular}{|c|c|c|c|c|c|c|}
\hline Feature & Level & $\begin{array}{l}\text { No (valid } \\
\text { observa- } \\
\text { tions) }\end{array}$ & $\begin{array}{l}\text { No NN pre- } \\
\text { sent (propor- } \\
\text { tion) }\end{array}$ & Odds ratio & $95 \% \mathrm{CI}$ & $P$ \\
\hline \multirow[t]{2}{*}{ Age } & $\leq 60$ years & 531 & $93(17.5 \%)$ & 0.76 & $0.54-1.07$ & 0.17 \\
\hline & $>60$ years & 554 & $77(13.9 \%)$ & & & \\
\hline \multirow[t]{2}{*}{ Gender } & Female & 530 & $79(14.9 \%)$ & 1.12 & $0.80-1.58$ & 0.50 \\
\hline & Male & 555 & $91(16.4 \%)$ & & & \\
\hline \multirow[t]{2}{*}{ History that the melanoma arose from a pigmented mole } & Yes & 583 & $92(15.8 \%)$ & 1.00 & $0.62-1.51$ & 1.0 \\
\hline & No & 285 & $45(15.8 \%)$ & & & \\
\hline \multirow[t]{2}{*}{ Melanoma in parents or siblings } & Yes & 75 & $15(20.0 \%)$ & 1.35 & $0.69-2.48$ & 0.32 \\
\hline & No & 959 & $150(15.6 \%)$ & & & \\
\hline \multirow[t]{2}{*}{ Non-cutaneous malignancy in parents } & Yes & 282 & $59(20.9 \%)$ & 1.63 & $1.12-2.36$ & 0.007 \\
\hline & No & 708 & $99(14.0 \%)$ & & & \\
\hline \multirow[t]{2}{*}{ Fitzpatrick skin phototype } & Bright (1-2) & 858 & $139(16.2 \%)$ & 1.15 & $0.73-1.84$ & 0.54 \\
\hline & Dark (3-4) & 201 & $29(14.4 \%)$ & & & \\
\hline \multirow[t]{2}{*}{ Skin nevus count } & $<50$ & 648 & $70(10.8 \%)$ & 2.53 & $1.79-3.60$ & $<0.0001$ \\
\hline & $\geq 50$ & 413 & $97(23.5 \%)$ & & & \\
\hline \multirow[t]{2}{*}{ Multiple lentigines solares } & Absent & 471 & $69(14.6 \%)$ & 1.19 & $0.84-1.68$ & 0.32 \\
\hline & Present & 591 & $100(16.9 \%)$ & & & \\
\hline \multirow[t]{8}{*}{ Primary melanoma location } & Left body site & 555 & $80(14.4 \%)$ & 0.99 & $0.68-1.44$ & 0.98 \\
\hline & Right body site & 440 & $63(14.3 \%)$ & & & \\
\hline & Lateralized & 995 & $143(14.4 \%)$ & 2.68 & $1.58-4.45$ & $<0.0001$ \\
\hline & Midline & 87 & $27(31.0 \%)$ & & & \\
\hline & Extremities & 541 & $65(12.0)$ & 1.850 & $1.28-2.69$ & $<0.0001$ \\
\hline & Trunk & 401 & $81(20.2 \%)$ & & & \\
\hline & Legs & 317 & $23(7.6 \%)$ & 2.94 & $1.67-5.31$ & $<0.0001$ \\
\hline & Arms & 224 & $42(18.8 \%)$ & & & \\
\hline \multirow[t]{2}{*}{ Melanoma with histologically associated skin nevus } & No & 271 & $52(19.2 \%)$ & 1.57 & $1.05-2.31$ & 0.019 \\
\hline & Yes & 684 & $90(13.2 \%)$ & & & \\
\hline \multirow[t]{2}{*}{ Primary melanoma ulceration } & Present & 291 & $42(14.4 \%)$ & 1.09 & $0.74-1.65$ & 0.64 \\
\hline & Absent & 751 & $117(15.6 \%)$ & & & \\
\hline \multirow[t]{3}{*}{ Leading nodal basin } & Neck & 158 & $26(16.5 \%)$ & Groin vs other & & 0.0002 \\
\hline & Axilla & 553 & $104(19.4 \%)$ & & & \\
\hline & Groin & 369 & $36(9.8 \%)$ & 2.13 & $1.42-3.25$ & \\
\hline \multirow[t]{2}{*}{ Lymphatic drainage } & Uni-directional & 871 & $116(13.2 \%)$ & 2.17 & $1.47-3.17$ & $<0.0001$ \\
\hline & Bi-directional & 212 & $53(25.0 \%)$ & & & \\
\hline \multirow[t]{2}{*}{ Pathological SN status } & SN-negative & 763 & $128(16.7 \%)$ & 1.34 & $0.91-2.01$ & 0.12 \\
\hline & SN-positive & 322 & $42(13.0 \%)$ & & & \\
\hline \multirow[t]{2}{*}{ Maximal metastasis diameter } & $\mathrm{MTD}>1 \mathrm{~mm}$ & 118 & $8(6.9 \%)$ & 2.74 & $1.19-7.12$ & 0.01 \\
\hline & $\mathrm{MTD} \leq 1 \mathrm{~mm}$ & 204 & $34(16.7 \%)$ & & & \\
\hline
\end{tabular}

$C I$ confidence interval, $N N$ nodal nevus, $S N$ sentinel lymph node, $M T D$ maximum diameter of the largest metastasis within the SNs

\section{SN-positive subpopulation}

Also in the presence of $\mathrm{SN}$ metastasis, in univariate analysis NN were associated with midline-located primary melanomas (30.4\% vs. $15.0 \%, P=0.019)$, bidirectional lymphatic drainage ( $24.6 \%$ vs. $9.9 \%, P=0.002)$, and skin nevus count of $\geq 50(22.4 \%$ vs. $7.3 \%, P<0.001)$. The history of life-threatening cancer in parents failed significance
(NN rates $19.9 \%$ vs $11.2 \%, P=0.18$ ). In contrast to $\mathrm{SN}$ negative patients, Breslow thickness $(P=0.005)$ as continuous variable turned out to be important. Breslow thickness was correlated with the MTD $(r=0.39, P<0001)$. A maximum metastasis diameter exceeding $1 \mathrm{~mm}$ was associated with a decreased probability of NN detection (18.5\% vs. $6.2 \%, P=0.010$ ) (Tables 1,3 ). Other features were non-significant. 
Table 2 Multivariate logistic regression analysis of factors predicting the probability of sentinel node nevi in the overall population

\begin{tabular}{lllr}
\hline Feature & Odds ratio & $95.0 \%$ CI & $P$ \\
\hline$\geq 50$ skin nevi & 2.29 & $1.52-3.45$ & $<0.001$ \\
Nodal basin other than groin & 2.30 & $1.44-3.68$ & $<0.001$ \\
Midline location of the primary melanoma & 0.49 & $0.27-0.89$ & 0.018 \\
Parental non-skin malignancy & 1.58 & $1.05-2.37$ & 0.029 \\
Pathological SN status & 1.34 & $0.85-2.13$ & 0.205 \\
Melanoma with histologically associated skin nevus & 1.15 & $0.75-1.77$ & 0.514 \\
Age/year & 0.99 & $0.98-1.01$ & 0.59 \\
\hline
\end{tabular}

CI confidence interval, $S N$ sentinel lymph node,

Table 3 Multivariate logistic regression analysis of factors predicting the probability of nodal nevi according to the pathological status of the sentinel lymph node

\begin{tabular}{|c|c|c|c|c|c|c|}
\hline \multirow[t]{2}{*}{ Feature } & \multicolumn{3}{|c|}{ SN status negative } & \multicolumn{3}{|c|}{ SN status positive } \\
\hline & Odds ratio & $95 \% \mathrm{CI}$ & $P$ & Odds ratio & $95 \% \mathrm{CI}$ & $P$ \\
\hline$\geq 50$ skin nevi & 2.22 & $1.43-3.57$ & $<0.001$ & 3.68 & $1.66-8.06$ & 0.001 \\
\hline SN from the neck or axilla (vs. groin) & 2.52 & $1.43-4.48$ & 0.001 & 1.84 & $0.85-4.03$ & 0.120 \\
\hline Non-cutaneous malignancy in parents & 1.39 & $0.86-2.24$ & 0.178 & 2.24 & $1.03-4.89$ & 0.041 \\
\hline Midline location of the primary melanoma & 1.82 & $0.93-3.58$ & 0.082 & 2.77 & $0.91-8.46$ & 0.073 \\
\hline Age / year & 0.99 & $0.98-1.01$ & 0.596 & 1.004 & $0.98-1.03$ & 0.710 \\
\hline Multiple solar lentigines & 1.09 & $0.69-1.72$ & 0.725 & 0.43 & $1.99-0.94$ & 0.034 \\
\hline MTD / mm & - & - & - & 0.69 & $0.48-0.99$ & 0.043 \\
\hline
\end{tabular}

$C I$ confidence interval, $S N$ sentinel lymph node, $M T D$ maximum diameter of the largest metastasis within the SN

In multivariate logistic regression (Table 3), the presence of more than 50 skin nevi, SNs draining the upper half of the body, and history of parental non-cutaneous cancers remained significant also in $\mathrm{SN}$-positive patients.

\section{Survival analysis}

SN-negative patients had approximately $4 \%$ decreased melanoma-specific 5-year survival when diagnosed with NN (hazard ratio 1.7 for NN present; 95\% CI 0.93-3.13, logrank test: $P=0.082$, Fig. 1A. Primary tumor-related risk factors did not differ significantly between the subgroups with and without $\mathrm{NN}$ (median Breslow thickness $1.4 \mathrm{~mm}$ for both (range $0.4-20.0 \mathrm{~mm}$ ), $P=0.650$, ulceration $24.4 \%$ vs. $23 \%, P=0.722$ ). There were no significant differences in recurrence-free survival $(P=0.32)$ and recurrence-free survival in the nodal basin $(P=0.15)$.

$\mathrm{SN}$-positive patients with $\mathrm{NN}$ had slightly better melanoma-specific survival than patients without NN (Fig. 1B). The difference in survival curves was not significant. It should be noted that $\mathrm{SN}$-positive patients with concurrent NN had a lower median primary tumor thickness than patients with only SN metastases (median Breslow thickness $1.6 \mathrm{~mm}$ (range $0.65-5.2 \mathrm{~mm}$ ) vs. $2.4 \mathrm{~mm}$ (range $0.4-15.0 \mathrm{~mm}$ ), $\mathrm{P}=0.005$ ) and also a lower median
MTD $(0.80 \mathrm{~mm}$ (range $0.02-5.0 \mathrm{~mm})$ vs. $1.6 \mathrm{~mm}$ (range $0.002-14.0 \mathrm{~mm}), P<0.001)$.

\section{Discussion}

$\mathrm{NN}$ are growth-arrested melanocytic clusters that are usually diagnosed in SNs draining melanoma, breast, vulvar, or penile cancer. NN and other benign inclusions in lymph nodes are addressed in a recent review article (Müller et al. 2021). Unlike most melanomas, NN usually have bland cytomorphology and no mitotic activity. With the exception of intranodal blue nevi, NN do not express HMB-45 or express it only weakly (Gonzàlez-Farré et al. 2020). Histological images of NN are shown in Fig. 2. Recently, p16 (mostly positive for NN, Fig. 2) (Piana et al. 2015) and PRAME (mostly negative for NN) (See et al. 2020) have been introduced in the differential diagnosis to SN metastases of melanoma.

The NN prevalence reported in the literature vary considerably, from 0 to 22\% (McCarthy et al. 1974; Fisher et al. 1994; Biddle et al. 2003; Holt et al. 2004; Gambichler et al. 2013; Piana et al. 2015; Smith et al. 2016; Kim et al. 2018; de Beer et al. 2019; Yamashita et al. 2020) The likelihood of an NN diagnosis is certainly influenced by many factors, including the type of cancer, the pathologic protocol used, 
Fig. 1 Melanoma-specific survival according to sentinel node (SN) status. A SN-negative patients with intranodal nevus (NN) show a slightly decreased survival rate. B SN-positive patients with the simultaneous diagnosis of $\mathrm{NN}$ and nodal metastasis fared slightly better than patients with $\mathrm{SN}$ metastasis only. The differences in the survival curves failed significance

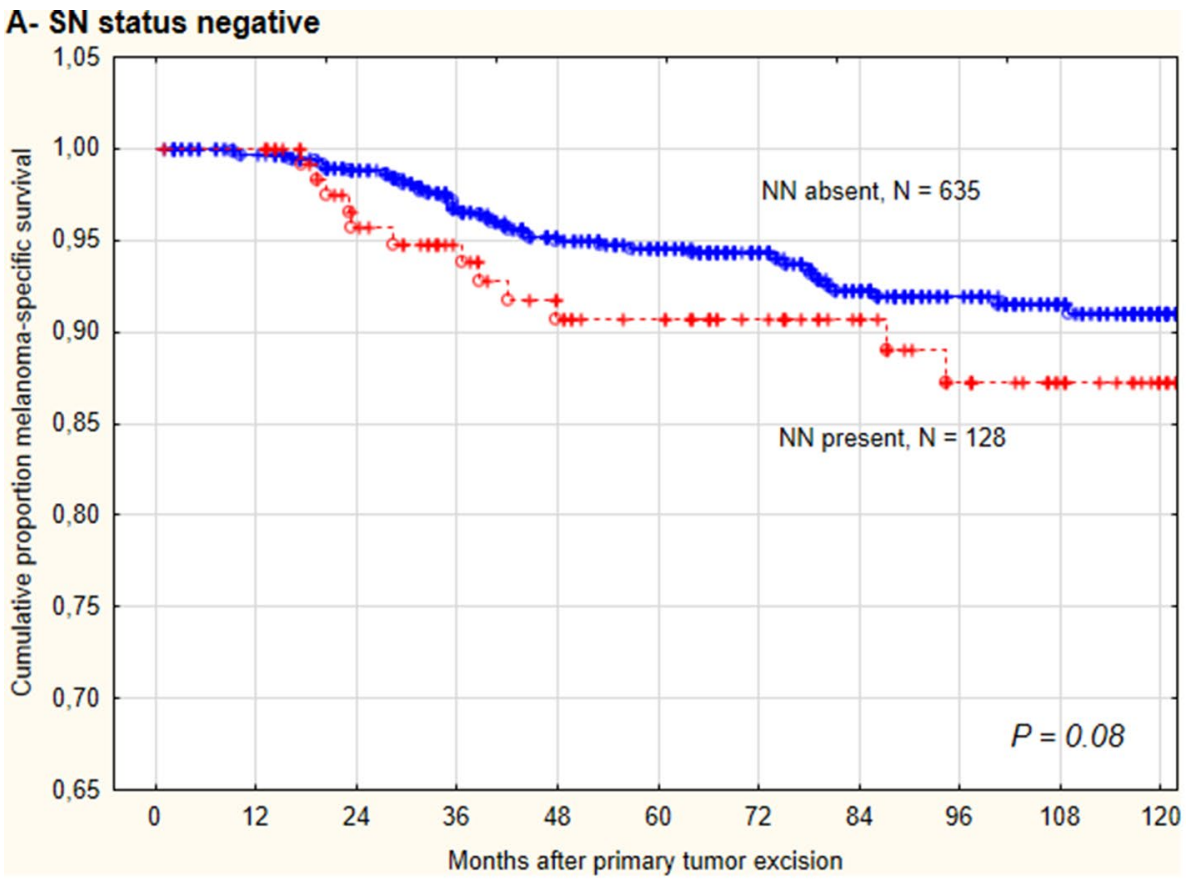

\section{B - SN status positive}

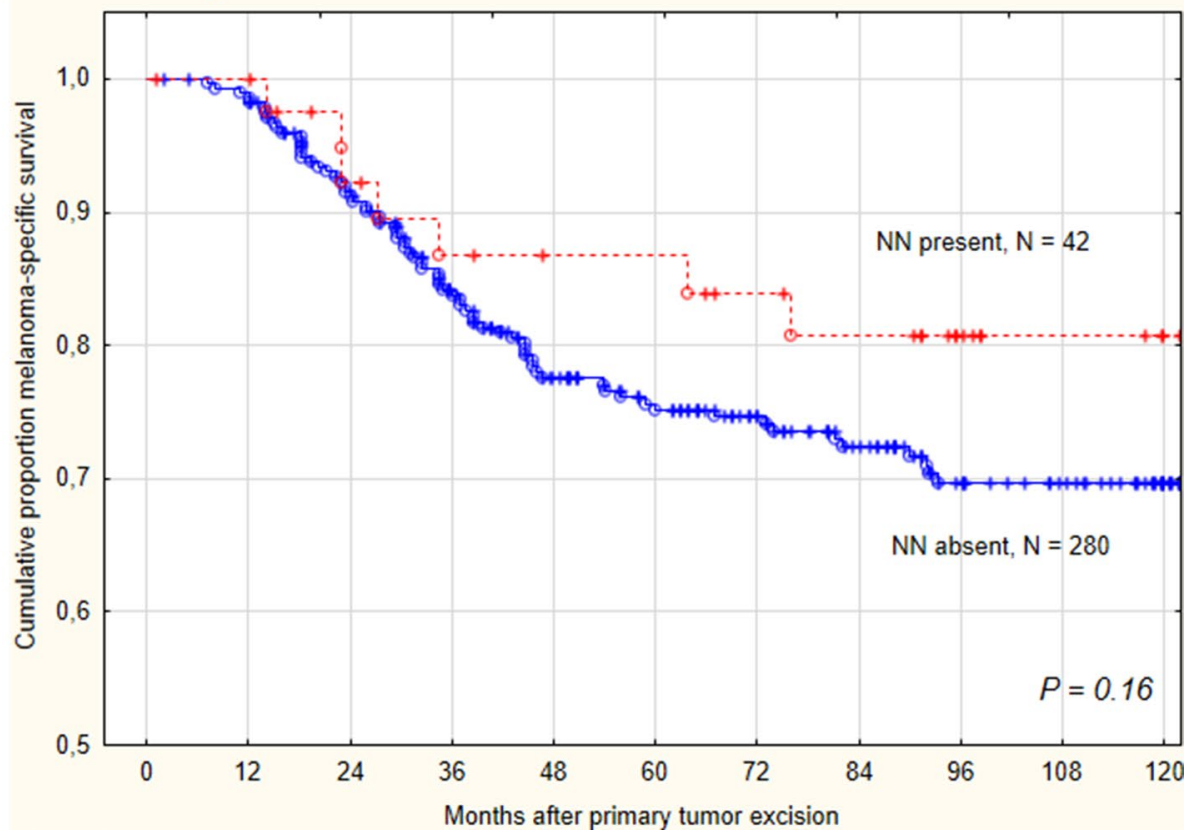

the lymphatic drainage conditions, the size of the lymph nodes, the number of lymph nodes removed, and the frequency and extent of malignant metastases. Using an extensive pathologic protocol, we observed an overall prevalence of $15.7 \%$ in a large population with SNB for cutaneous melanomas. The specific prevalences for cervical, axillary, and groin SNs were $16.5 \%, 19.4 \%$, and $9.8 \%$, respectively.

Regarding etiology, it has been speculated that during embryogenesis NN develop from melanocytic precursor cells that migrate from the neural crest to the skin, taking the dorsolateral developmental pathway (Kos et al. 2001).
Melanocytic precursors migrate through the mesenchyme, where the lymphatic system is formed almost simultaneously. It has been argued that the location of NN predominantly in fibrous structures of lymph nodes, the association of NN with congenital nevi (Bowen et al. 2015), and the mere existence of neurocutaneous melanosis would support the theory of cell arrest during embryogenesis (Carson et al. 1996).

On the other hand, there are a number of good arguments that NN stem from melanocytic cells of the skin that have migrated via afferent lymphatic vessels: (1) In agreement 


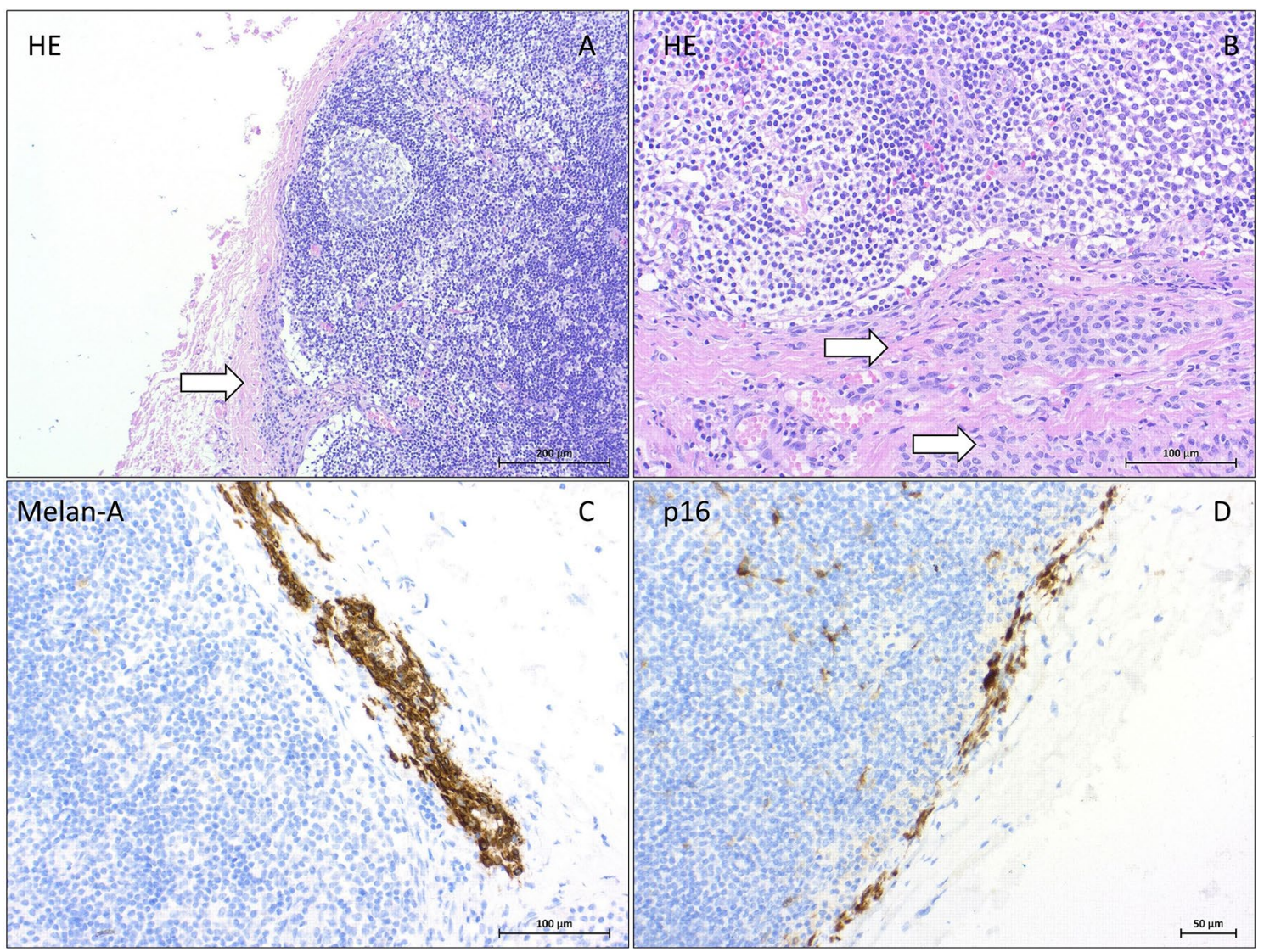

Fig. 2 Histology and immunohistochemistry of melanocytic nevi in a sentinel lymph nodes: In the H\&E staining, small groups of melanocytic cells in the nodal capsule $(\Rightarrow)$ show bland cytomorphology. Localization of melanocytes within the capsule or trabeculae of

with Carson et al. (1996), at least in univariate analysis, we documented a significantly increased probability of $\mathrm{NN}$ in patients whose primary melanomas were histologically associated with a cutaneous nevus. (2) Invasion of lymphatic vessels by nevus cells has been observed within cutaneous nevi (McCarthy et al. 1974; Bell et al. 1979; Subramony and Lewin 1985; Hara 1993). (3) Cutaneous nevi in the drainage area of lymph nodes with NN have been observed in several case series (McCarthy et al. 1974; Hara 1993; Fontaine et al. 2002; Holt et al. 2004; Hu et al. 2020) (4) NN have been much more frequent in SNs than in non-SNs (Carson et al. 1996; Holt et al. 2004; Gambichler et al. 2013) or lymphadenectomy specimens.(Ridolfi et al. 1977; Fisher et al. 1994) (5) NN have not been described in deeply located nodes of the thorax or abdomen, which do not drain the skin. (McCarthy et al. 1974) (6) Lymph nodes from melanoma surgery are more likely to contain NN than superficial lymph nodes excised for other cancers (Biddle et al. 2003; Piana et al. 2015) (7) electron microscopic studies of NN have revealed ultrastructural features identical to those of intradermal nevus cells (Erlandson and Rosen 1982). (8) Using the lymph node strongly supports the diagnosis of a benign NN (A $\mathrm{HE} \times 100 ; \mathbf{B} \mathrm{HE} \times 200)$. Positive cytoplasmatic staining for Melan A $(\mathbf{C} \times 200)$ and positive nuclear staining for p16 $(\mathbf{D} \times 200)$

next-generation sequencing, comparison of mutation profiles in primary melanomas and corresponding $\mathrm{NN}$ suggested that $\mathrm{NN}$ descend from cutaneous melanocytes, rather than from primary MM or arrested progenitor cells (Gambichler et al. 2021).

We demonstrated that $\mathrm{NN}$ can be found in SNs related to all growth patterns of primary melanoma. This includes rare growth patterns such as desmoplastic and nevoid melanomas. The SNs of three out of four patients with malignant blue nevus displayed an NN.

Using multivariate analyses, we discovered a very robust association between multiple nevi of the skin and the prevalence of NN, both in SN-negative and SN-positive patients. To the best of our knowledge, only 1 small case-control study including 22 patients with $\mathrm{NN}$ has confirmed this observation (Ribero et al. 2017). We found that the midline location of the primary melanoma as well as bidirectional lymphatic drainage resulted in a higher number of excised SNs, which logically increases the chance of detecting NN. As many as $31 \%$ of patients with upper trunk melanoma had bidirectional lymphatic drainage (Kretschmer et al. 2019). A 
lower NN prevalence in inguinal lymph nodes has already been reported (McCarthy et al. 1974; Gambichler et al. 2013). By reporting prevalence for cervical SNs for the first time, we can state a significantly higher NN prevalence for SNs draining the upper part of the body, which hold true in multivariate logistic regression. This coincides with the distribution of cutaneous nevi. Also their density seems to be higher on the upper half of the body (Echeverría et al. 2014). Many studies have shown an association between sun exposure and the number of skin nevi. Cervical lymph nodes drain a relatively small area of skin that is chronically exposed to sunlight. Axillary lymph nodes drain large areas of intermittently sun-exposed skin, which is characterized by high skin nevus count (Newton-Bishop et al. 2010). In a longitudinal study, an increase in skin nevi after 15 years of observation was registered only on the upper parts of the body.(Ribero et al. 2021) We confirmed that primary melanomas located at the arm were associated with higher NN rates than leg-located melanomas (Yamashita et al. 2020). It has been shown that also the density of cutaneous nevi of the arms is greater than that of nevi of the legs (Harrison et al. 1999). Interestingly, the frequency of ultraviolet of ultraviolet light-associated mutations was relatively high not only in primary melanomas but also in NN (Gambichler et al. 2021). Moreover, ultraviolet light seems to induce the expression of growth factors involved in the early migration process of malignant melanocytes (Wäster et al. 2017).

Like others, we found no sex-specific difference in the $\mathrm{NN}$ rates. Fitzpatrick skin phototype was not associated with $\mathrm{NN}$, an observation not previously reported. The influence of multiple solar lentigines was not convincing because it had different signs depending on SN status (Table 3).

We can only speculate about the possible implications of our surprising observation that patients with melanoma in whom at least one parent had undergone another life-threatening cancer were significantly more likely to be diagnosed with NN. In parallel, multiple nevi of the skin were also highly significantly associated with a history of cancer in the parents. Genome-wide association studies have described a larger number of susceptibility loci for melanoma that are related not only to nevus count, pigment type, and tanning response but also to telomere maintenance and DNA repair mechanisms. From this perspective, a link between multiple melanocytic nevi in skin and lymph nodes and a susceptibility to develop other tumor entities seems potentially explainable (Landi et al. 2020).

Analyzing $56 \mathrm{SN}$-negative patients with NN, Yamashita et al. observed a non-significantly lower recurrence-rate, compared with purely $\mathrm{SN}$-negatives and suggested a metastasis-protective effect of NN (Yamashita et al. 2020). Most previous studies (Gambichler et al. 2013; Smith et al. 2016; Kim et al. 2018; de Beer et al. 2019; El Sharouni et al. 2021) have concluded that the presence of $\mathrm{NN}$ in $\mathrm{SN}$-negative cases does not affect survival. We can generally confirm this statement but found a trend toward slightly higher mortality in SN-negatives with NN (Fig. 1A). A large Dutch registry study of 11,274 patients confirmed a similar trend. (de Beer et al. 2019) Possibly, in daily practice SN metastases are misinterpreted as NN in rare cases. For example, metastases of nevoid melanomas can strongly resemble NN (Biddle et al. 2003; Davis et al. 2016). Very small metastases, metastases in intracapsular lymphatic vessels, $\mathrm{NN}$ in the presence of concurrent $\mathrm{SN}$ metastases, and lack of HMB-45 reactivity of SN metastases represent further diagnostic pitfalls (Biddle et al. 2003; Gonzàlez-Farré et al. 2020; Lezcano et al. 2020). Very rarely, metastases of other kinds of cancer, e. g., lobular breast cancer may mimic NN (Fisher et al. 1994).

Prevalence and prognostic impact of NN diagnosis in SN-positive patients have not been reported. In our study, patients who were both $\mathrm{SN}$ and NN positive had a slightly higher survival rate than $\mathrm{SN}$-positive patients without $\mathrm{NN}$. We demonstrated that the likelihood of an NN diagnosis decreases with increasing Breslow thickness and, relatedly, with increasing $\mathrm{SN}$ metastasis size. This alone explains why the SN-positive patients with concurrent NN diagnosis fared somewhat better (Fig. 1B).

Our study has several limitations, including retrospective data analysis, the failure to record the number of SNs affected with NN per subject, the microanatomical location of NN within SNs, and the histologic specificities of NN according to the growth patterns of primary melanoma. Multiple testing is another problem; we cannot exclude the possibility that some error probabilities are due to chance.

In summary, using multivariate analyses, we found a highly significantly increased prevalence of $\mathrm{NN}$ in SNs in patients with upper body melanomas, midline primary melanomas, and those with more than 50 nevi of the skin. A history of non-cutaneous malignancies in parents was associated with increased $\mathrm{NN}$ prevalence, as were multiple nevi of the skin. When the primary melanoma was histologically associated with a cutaneous nevus, NNs were also more frequently found in SNs. In SN-positive patients, the likelihood of an NN diagnosis decreased with increasing metastatic diameter. The slightly worse melanoma-specific survival of SN-negative patients with $\mathrm{NN}$ that we observed suggests that careful differentiation of NN and SN metastases is sometimes difficult and should be done very carefully.

Acknowledgements We would like to express our very great appreciation to Dr. Hans-Peter Bertsch for his valuable contribution to develop the protocols for pathologic workup and reporting.

Funding Open Access funding enabled and organized by Projekt DEAL. Open Access funding enabled and organized by Projekt DEAL. 


\section{Declarations}

Conflict of interest None declared.

Open Access This article is licensed under a Creative Commons Attribution 4.0 International License, which permits use, sharing, adaptation, distribution and reproduction in any medium or format, as long as you give appropriate credit to the original author(s) and the source, provide a link to the Creative Commons licence, and indicate if changes were made. The images or other third party material in this article are included in the article's Creative Commons licence, unless indicated otherwise in a credit line to the material. If material is not included in the article's Creative Commons licence and your intended use is not permitted by statutory regulation or exceeds the permitted use, you will need to obtain permission directly from the copyright holder. To view a copy of this licence, visit http://creativecommons.org/licenses/by/4.0/.

\section{References}

Bell ME, Hill DP, Bhargava MK (1979) Lymphatic invasion in pigmented nevi. Am J Clin Pathol 72:97-100

Biddle DA, Evans HL, Kemp BL, El-Naggar AK, Harvell JD, White WL, Iskandar SS, Prieto VG (2003) Intraparenchymal nevus cell aggregates in lymph nodes: a possible diagnostic pitfall with malignant melanoma and carcinoma. Am J Surg Pathol 27:673-681

Bowen AR, Duffy KL, Clayton FC, Andtbacka RH, Florell SR (2015) Benign melanocytic lymph node deposits in the setting of giant congenital melanocytic nevi: the large congenital nodal nevus. J Cutan Pathol 42:832-839

Carson KF, Wen DR, Li PX, Lana AM, Bailly C, Morton DL, Cochran AJ (1996) Nodal nevi and cutaneous melanomas. Am J Surg Pathol 20:834-840

Davis J, Patil J, Aydin N, Mishra A, Misra S (2016) Capsular nevus versus metastatic malignant melanoma-a diagnostic dilemma. Int J Surg Case Rep 29:20-24

de Beer FSA, van Diest PJ, Sigurdsson V, El Sharouni M (2019) Intranodal nevi in sentinel node-negative patients with cutaneous melanoma does not influence survival. J Eur Acad Dermatol Venereol 33:2291-2295

Echeverría B, Bulliard JL, Guillén C, Nagore E (2014) Indicators for the total number of melanocytic naevi: an adjunct for screening campaigns. Observational study on 292 patients. Br J Dermatol 170:144-149

El Sharouni MA, Laeijendecker AE, Suijkerbuijk KP, Witkamp AJ, Sigurdsson V, van Diest PJ, van Gils CH, Blokx WA (2021) High discordance rate in assessing sentinel node positivity in cutaneous melanoma: expert review may reduce unjustified adjuvant treatment. Eur J Cancer 149:105-113

Erlandson RA, Rosen PP (1982) Electron microscopy of a nevus cell aggregate associated with an axillary lymph node. Cancer 49:269-272

Fisher CJ, Hill S, Millis RR (1994) Benign lymph node inclusions mimicking metastatic carcinoma. J Clin Pathol 47:245-247

Fontaine D, Parkhill W, Greer W, Walsh N (2002) Nevus cells in lymph nodes: an association with congenital cutaneous nevi. Am J Dermatopathol 24:1-5

Gambichler T, Scholl L, Stücker M, Bechara FG, Hoffmann K, Altmeyer P, Othlinghaus N (2013) Clinical characteristics and survival data of melanoma patients with nevus cell aggregates within sentinel lymph nodes. Am J Clin Pathol 139:566-573
Gambichler T, Rohrmoser EM, Horny K, Sucker A, Schadendorf D, Skrygan M, Susok L, Stücker M, Becker JC (2021) Comparison of mutation profiles in primary melanomas and corresponding nodal naevi using next-generation sequencing. Clin Exp Dermatol. https://doi.org/10.1111/ced.14951

Gonzàlez-Farré M, Ronen S, Keiser E, Prieto VG, Aung PP (2020) Three types of nodal melanocytic nevi in sentinel lymph nodes of patients with melanoma: pitfalls, immunohistochemistry, and a review of the literature. Am J Dermatopathol 42:739-744

Hara K (1993) Melanocytic lesions in lymph nodes associated with congenital naevus. Histopathology 23:445-451

Harrison SL, Buettner PG, MacLennan R (1999) Body-site distribution of melanocytic nevi in young Australian children. Arch Dermatol 135:47-52

Holt JB, Sangueza OP, Levine EA, Shen P, Bergman S, Geisinger KR, Creager AJ (2004) Nodal melanocytic nevi in sentinel lymph nodes. Correlation with melanoma-associated cutaneous nevi. Am J Clin Pathol 121:58-63

Hu J, Ren M, Cai X, Zhang Y, Lv JJ, Kong YY (2020) Nevus cell aggregates massively occupying parenchyma of an external iliac lymph node: a case report and review of the literature. J Cutan Pathol 47:1175-1180

Kim HJ, Seo JW, Roh MS, Lee JH, Song KH (2018) Clinical features and prognosis of Asian patients with acral lentiginous melanoma who have nodal nevi in their sentinel lymph node biopsy specimen. J Am Acad Dermatol 79:706-713

Kos R, Reedy MV, Johnson RL, Erickson CA (2001) The wingedhelix transcription factor FoxD3 is important for establishing the neural crest lineage and repressing melanogenesis in avian embryos. Development 128:1467-1479

Kretschmer L, Bertsch HP, Bardzik P, Meller J, Hellriegel S, Thoms KM, Schon MP, Sahlmann CO (2015) The impact of nodal tumour burden on lymphoscintigraphic imaging in patients with melanomas. Eur J Nucl Med Mol Imaging 42:231-240

Kretschmer L, Hellriegel S, Cevik N, Hartmann F, Thoms KM, Schön MP (2019) Axillary sentinel node biopsy in prone position for melanomas on the upper back or nape. J Plast Surg Hand Surg 53:221-226

Kretschmer L, Mitteldorf C, Hellriegel S, Leha A, Fichtner A, Ströbel P, Schön MP, Bremmer F (2021) The sentinel node invasion level (SNIL) as a prognostic parameter in melanoma. Mod Pathol 34:1839-1849

Landi MT, Bishop DT, MacGregor S, Machiela MJ, Stratigos AJ, Ghiorzo P, Brossard M, Calista D, Choi J, Fargnoli MC, Zhang T, Rodolfo M, Trower AJ, Menin C, Martinez J, Hadjisavvas A, Song L, Stefanaki I, Scolyer R, Yang R, Goldstein AM, Potrony M, Kypreou KP, Pastorino L, Queirolo P, Pellegrini C, Cattaneo L, Zawistowski M, Gimenez-Xavier P, Rodriguez A, Elefanti L, Manoukian S, Rivoltini L, Smith BH, Loizidou MA, Del Regno L, Massi D, Mandala M, Khosrotehrani K, Akslen LA, Amos CI, Andresen PA, Avril MF, Azizi E, Soyer HP, Bataille V, Dalmasso B, Bowdler LM, Burdon KP, Chen WV, Codd V, Craig JE, Dębniak T, Falchi M, Fang S, Friedman E, Simi S, Galan P, Garcia-Casado Z, Gillanders EM, Gordon S, Green A, Gruis NA, Hansson J, Harland M, Harris J, Helsing P, Henders A, Hočevar M, Höiom V, Hunter D, Ingvar C, Kumar R, Lang J, Lathrop GM, Lee JE, Li X, Lubiński J, Mackie RM, Malt M, Malvehy J, McAloney K, Mohamdi H, Molven A, Moses EK, Neale RE, Novaković S, Nyholt DR, Olsson H, Orr N, Fritsche LG, Puig-Butille JA, Qureshi AA, Radford-Smith GL, Randerson-Moor J, Requena C, Rowe C, Samani NJ, Sanna M, Schadendorf D, Schulze HJ, Simms LA, Smithers M, Song F, Swerdlow AJ, van der Stoep N, Kukutsch NA, Visconti A, Wallace L, Ward SV, Wheeler L, Sturm RA, Hutchinson A, Jones K, Malasky M, Vogt A, Zhou W, Pooley KA, Elder DE, Han J, Hicks B, Hayward NK, Kanetsky PA, Brummett C, 
Montgomery GW, Olsen CM, Hayward C, Dunning AM, Martin NG, Evangelou E, Mann GJ, Long G, Pharoah PDP, Easton DF, Barrett JH, Cust AE, Abecasis G, Duffy DL, Whiteman DC, Gogas H, De Nicolo A, Tucker MA, Newton-Bishop JA, Peris K, Chanock SJ, Demenais F, Brown KM, Puig S, Nagore E, Shi J, Iles MM, Law MH (2020) Genome-wide association metaanalyses combining multiple risk phenotypes provide insights into the genetic architecture of cutaneous melanoma susceptibility. Nat Genet 52:494-504

Lezcano C, Pulitzer M, Moy AP, Hollmann TJ, Jungbluth AA, Busam KJ (2020) Immunohistochemistry for PRAME in the distinction of nodal nevi from metastatic melanoma. Am J Surg Pathol 44:503-508

McCarthy SW, Palmer AA, Bale PM, Hirst E (1974) Naevus cells in lymph nodes. Pathology 6:351-358

Müller CSL, Müller SG, Vogt T, Pföhler C (2021) Current concepts of ectopic nodal inclusions with special emphasis on nodal nevi. J Dtsch Dermatol Ges 19:1145-1157

Newton-Bishop JA, Chang YM, Iles MM, Taylor JC, Bakker B, Chan M, Leake S, Karpavicius B, Haynes S, Fitzgibbon E, Elliott F, Kanetsky PA, Harland M, Barrett JH, Bishop DT (2010) Melanocytic nevi, nevus genes, and melanoma risk in a large case-control study in the United Kingdom. Cancer Epidemiol Biomark Prev 19:2043-2054

Pflugfelder A, Kochs C, Blum A, Capellaro M, Czeschik C, Dettenborn T, Dill D, Dippel E, Eigentler T, Feyer P, Follmann M, Frerich B, Ganten MK, Gartner J, Gutzmer R, Hassel J, Hauschild A, Hohenberger P, Hubner J, Kaatz M, Kleeberg UR, Kolbl O, Kortmann RD, Krause-Bergmann A, Kurschat P, Leiter U, Link H, Loquai C, Loser C, Mackensen A, Meier F, Mohr P, Mohrle M, Nashan D, Reske S, Rose C, Sander C, Satzger I, Schiller M, Schlemmer HP, Strittmatter G, Sunderkotter C, Swoboda L, Trefzer U, Voltz $\mathrm{R}$, Vordermark D, Weichenthal M, Werner A, Wesselmann S, Weyergraf AJ, Wick W, Garbe C, Schadendorf D, D. German Society of (2013) S3-guideline "diagnosis, therapy and follow-up of melanoma"- -short version. J Dtsch Dermatol Ges 11:563-602

Piana S, Tagliavini E, Ragazzi M, Zanelli M, Zalaudek I, Ciarrocchi A, Valli R (2015) Lymph node melanocytic nevi: pathogenesis and differential diagnoses, with special reference to p16 reactivity. Pathol Res Pract 211:381-388
Ribero S, Longo C, Specchio F, Piana S, Castagnetti F, Moscarella E, Lallas A, Alfano R, Argenziano G (2017) Lymph nodes' capsular naevi are associated with high naevus count in melanoma patients: a case-control study. Melanoma Res 27:274-276

Ribero S, Zugna D, Spector T, Bataille V (2021) Natural history of naevi: a two-wave study. Br J Dermatol 184:289-295

Ridolfi RL, Rosen PP, Thaler H (1977) Nevus cell aggregates associated with lymph nodes: estimated frequency and clinical significance. Cancer 39:164-171

Scolyer RA, Murali R, McCarthy SW, Thompson JF (2008) Pathologic examination of sentinel lymph nodes from melanoma patients. Semin Diagn Pathol 25:100-111

See SHC, Finkelman BS, Yeldandi AV (2020) The diagnostic utility of PRAME and p16 in distinguishing nodal nevi from nodal metastatic melanoma. Pathol Res Pract 216:153105

Smith OJ, Coelho JA, Trevatt AE, Ross GL (2016) Clinical significance of intra-nodal naevi in sentinel node biopsies for malignant melanoma. Eur J Surg Oncol 42:1427-1431

Steward F, Copeland M (1931) Neurogenic sarcoma. Am J Cancer 15:1235-1320

Subramony C, Lewin JR (1985) Nevus cells within lymph nodes. Possible metastases from a benign intradermal nevus. Am J Clin Pathol 84:220-223

Wäster P, Orfanidis K, Eriksson I, Rosdahl I, Seifert O, Öllinger K (2017) UV radiation promotes melanoma dissemination mediated by the sequential reaction axis of cathepsins-TGF- $\beta 1-F A P-\alpha$. Br J Cancer 117:535-544

Yamashita TS, Pockaj BA, Bagaria SP, Flotte TJ, Fahy AS, de Azevedo RU, Harmsen WS, Block MS, Jakub JW (2020) Clinical significance of SLN benign capsular nevi in patients with melanoma. $\mathrm{J}$ Surg Oncol 122:1043-1049

Publisher's Note Springer Nature remains neutral with regard to jurisdictional claims in published maps and institutional affiliations. 